\title{
Early Maladaptive Schemas, Working Memory and Academic Performances of Moroccan Students
}

\author{
A. Ahami', K. Mammad1', F.-Z. Azzaoui'², S. Boulbaroud³, F.-Z. Rouim¹, S. Rusinek ${ }^{4}$ \\ ${ }^{1}$ Unit of Neuroscience and Applied Nutrition, Laboratory of Nutrition, Health and Environment, Department of Biology, \\ Faculty of Science, Kenitra, Morocco \\ ${ }^{2}$ Laboratory of Biology and Health, URAC 34,Department of Biology, Faculty of Science Ben M'Sik, Hassan II University, \\ Casablanca, Morocco \\ ${ }^{3}$ Department of Biology, Polydisciplinary Faculty, Sultan Moulay Sliman University, Beni Mellal, Morocco \\ ${ }^{4}$ Unit of Formation and Research of Psychology, University of Lille-III, New Town of Ascqcedex, France \\ Email: khaoula.mammad@gmail.com
}

How to cite this paper: Ahami, A., Mammad, K., Azzaoui, F.-Z., Boulbaroud, S., Rouim, F.-Z. and Rusinek, S. (2017) Early Maladaptive Schemas, Working Memory and Academic Performances of Moroccan Students. Open Journal of Medical Psycho$\log$, 6, 53-65.

https://doi.org/10.4236/ojmp.2017.62004

Received: November 29, 2016

Accepted: March 28, 2017

Published: March 31, 2017

Copyright $(9) 2017$ by authors and Scientific Research Publishing Inc. This work is licensed under the Creative Commons Attribution International License (CC BY 4.0).

http://creativecommons.org/licenses/by/4.0/

\begin{abstract}
Our aim is to study the early maladaptive schemas and the memory span abilities and to evaluate the relationship between these schemas and the memory in one side and academic performance in the other side among Moroccan students. A cross-sectional study is conducted among 212 students, randomly selected from different institutions of the IBN TOFAIL University, located in the city of Kenitra (NW of Morocco). Three neurocognitive tests are used: the short version of the Early Maladaptive Schemas Questionnaire to evaluate the early maladaptive schemas (EMS), the sub-test of the Wechsler to evaluate the working memory among these subjects, and a general questionnaire about socio-economic data, nutritional and mental health status and also, academic performances of each student. The obtained results showed some significant negative correlations between forward memory span and activated schema, and significant negative correlations are registered between backward memory span and activated schema. More, thirty-three percent of students passed the exams of the autumn term against $67 \%$ who failed it. Moreover, significant negative correlations are registered between the schemas and the number of Units validated in the autumn term. In addition, fifty-three percent of students had a normal forward memory, $47 \%$ had an excellent forward memory and no one had pathological one. However, $63 \%$ had a pathological backward memory span, $28 \%$ had normal memory and $9 \%$ had an excellent backward memory. The EMS appeared in connection with the student's working memory and the academic performance. Deeper investigations are needed to understand this relationship and also to study other possible factors that could
\end{abstract}


affect this important neurocognitive function.

\section{Keywords}

Early Maladaptive Schemas, Working Memory, Academic Performance, Effect

\section{Introduction}

In general terms, a schema can be defined as a structure, framework, theme, or pattern of cognitive content [1]. Beck considered that maladaptive schemas reflected deeply rooted patterns of distorted thinking about the world, oneself and one's relationship with others [2]. Schemas are considered to be highly generalized, resistant to change and exert a strong influence over cognition, and this influence is exerted through information processing at the unconscious level [3].

Young and colleagues distinguish between 18 EMSs that are organized in five domains, which correspond to the frustration of five basic psychological needs in childhood: secure attachment, autonomy, realistic limits, self-directedness, and playfulness [4].

Furthermore, the existence of schemas obviates the need to mentally reinvent the wheel with each new experience, so incoming information can be compared and filtered [5]. Schemas act as screening templates to determine what is processed, and thereby distort and bias the understanding of information [6] [7]. Research indicates that information processing is biased in favor of maintaining the status quo with respect to schema content. For example, according to young and co-workers, people are relatively better at remembering schema-consistent information, tend to make errors in a schema-consistent pattern, and interpret new information to support pre-existing schemas [8].

Early maladaptive schemas may result from a frustration of these basic needs by interaction between the child's innate temperament and dysfunctional experiences with parents, siblings, and peers during the first few years of life [9] [10].

Young and co-workers define an early maladaptive schema as: A broad, pervasive theme or pattern; comprised of memories, emotions, cognitions, and bodily sensations; regarding oneself and one's relationship with others; developed during childhood or adolescence; elaborated throughout one's lifetime; dysfunctional to a significant degree [8].

On the other hand, the information passes from the sensory memory into the working memory (WM), where it is either processed or discarded. The brain categorizes that information and moves it into long-term memory, where it is stored in knowledge structures called "schemas". These organize information according to how you use it. Therefore, for example, you have schemas for different concepts, and you have behavioural schemas for actions.

The WM must be maintained in its temporary storage of days and cross them. It is also involved in rules processing, performing calculation, and inhibiting unnecessary false information. It is also involved in all reasoning tasks such as 
problem solving. So the WM is closely linked to executive functions, it determines the number of variables that can be processed at the same time [11]. It is also involved increativity, if we define it as the act, which tends to find a presence in absence, but also the act of finding a new solution to a new problem. Therefore, computational research also showed the important role of working memory inaction categorization, planning, reasoning, language comprehension and problem solving. As well, WM is responsible for temporarily maintaining and manipulating information during cognitive activity [12]. It has been found to be closely related to a wide range of high-level cognitive abilities such as reasoning, problem-solving, and learning [13]. In addition, WM is related to academic achievement in the domain of reading [14], writing [15], mathematics, and science [16] [17].

Baddeley and Hitch's model of WM as a multiple-component system consisting of a phonological loop, a visuo-spatial sketchpad, and a central executive started the age of decomposing WM into different components [18]. The same idea is reflected in other WM models that followed. Although researchers differ in their specifications of WM subsystems, most agree that WM includes multiple subsystems working together to activate task-related information, maintain activation, and manipulate information during the performance of cognitive tasks [19]. The evolution of WM models shows that ideas about WM have shifted towards a more dynamic and systematic view. Like Miyake and Shah's effort to provide, a synthesized definition of WM, Oberauer and co-workers proposed a hierarchical model of WM based on factor analysis of 23 WM tasks. In their definition, WM was depicted with two higher-order factors content and function. Verbal and numerical WM and spatial WM were the two subfactors of the content factor. The first subfactor of function is responsible for the storage, transformation, and coordination of information and the second subfactor combines supervision and processing speed [20].

Baddeley's model represents the most extensively investigated theoretical construct of working memory [18] [21]. It is used for active temporary storage and manipulation of information within the time range of a few seconds, and is an important component for many higher cognitive functions. Instead of all information going into one single store; there are different systems for different types of information. It consists of a central executive, which controls and coordinates the operation of two subsystems: the phonological loop and the visuo-spatial sketchpad: Central Executive: Drives the whole system, and allocates data to the subsystems (Visuo-Spatial Sketchpad \& phonological loop). It also deals with cognitive tasks such as mental arithmetic and problem solving; Visuo-Spatial Sketchpad (inner eye: VSS): Stores and processes information in a visual or spatial form. The VSS is used for navigation; the phonological loop is the part of working memory that deals with spoken and written material. It can be used to remember a phone number. It consists of two parts:

- Phonological Store (inner ear)-linked to speech perception Holds information in speech-based form for $1-2$ seconds. 
- Articulatory control process (inner voice)-linked to speech production. Used to rehearse and store verbal information from the phonological store.

The aim of this study is to investigate the influence of early maladaptive schemas on the functioning of the working memory and its capacity, and to verify if the early maladaptive schemas that are activated in the individual may influence his academic performance.

\section{Subjects, Materials and Methods}

The present research is cross-sectional study, realized during May-June 2013, among 212 Moroccan students aged between 17 and 21 years. All of them are students in the first year in different institutions of the IBN TOFAIL University; Faculty of Sciences (50\%), Faculty of Letters \& Human Sciences (30\%), Faculty of Law and Economic Sciences (8\%) and National School of Applied Sciences (ENSA) (7\%).

Two questionnaires are used in this study; the first one is about the general status of students, and the second one is the translated short version of early maladaptive schemas of Young (EMS) [22].

Moreover, the Subtest of Wechsler (Digit Span) WAIS III is used for evaluation of working memory among these students.

\section{1. $1^{\text {st }}$ Questionnaire}

An investigation by standardized questionnaire includes socio-demographic data of students, academic performances and some questions about nutrition and mental health status.

\subsection{2nd Questionnaire: Early Maladaptive Schemas for Adult}

The questionnaire about EMS of anxiety consists of 65 statements such as: "Nobody really understands me", which are asked to respond by circling a number ranging from 1 to 6 (when the number is high then the person considers that the statement corresponding) (Questionnaire of Schmidt et al., [23], French version of Rusinek [22].

13 schemas are evaluated:

- Abandonment: Five items on the feeling that appreciates relationships with others will stop as always.

- Mistrust: Five items related to mistrust towards others.

- Emotional deprivation: five items representing past and present complaint about the lack of emotional sharing with others, the lack of consideration and affection.

- Social isolation: five items on the themes of loneliness, rejection of others, inability to invest in social relations.

- Dependence: Five items son the need of others to understand what is happening and performs actions.

- Vulnerability: five items for fear of impending disaster. 
- Insufficient self-control: Seven items linked by easy nervousness, unwillingness to complete the tasks, the refusal to act against his/her will.

- Self-sacrifice: five items on unlimited devotion to others.

- Emotional inhibition: five items related to the inability to express feelings.

- Unrelenting standards: five items whose main themes are the desire of perfection for oneself, inability to be satisfied with actions.

- Incompetence: five items on the theme of belief inability level and lower than that of other successful.

- Enmeshment; five items on the inability to break away from the opinion and influence of parents and partners.

- Fear of loss of control: three items son fear to react impulsively and hurt others physically or morally.

\subsection{Subtest of Wechsler (WAISIII Digit Span)}

There are two parts to the Memory for Digit Span assessment: Digits Forward and Digits Backward.

Students repeating a list of digits in direct order increase the number of digits in As: the student listens to and repeats a sequence of numbers told by the interviewer and in the second part, the student listens to a sequence of numbers and repeats them in reverse order. In both parts, the length of each sequence of numbers increases as the student correctly responds. We start with two digits. Then continue with four, then five ... Digits Forward primarily taps short-term auditory memory while Digits Backward measures the child's ability to manipulate verbal information while in temporary storage. Miller defined the normal range for Digit Span forward as a maximum span of $7 \pm 2$ digits [24].

\subsection{Statistical Analysis}

The descriptive study is realized using calculation of frequency, and the correlation between the early maladaptive schemas and Digit span and the number of Units which the student validated in his first year at university, they were evaluated using of the Spearman's correlation coefficient $\rho$.

\section{Results}

\subsection{Characteristics of the Sample}

\subsubsection{Distribution of the Gender, the Age and the Success in the First Year}

The results showed that our simpler is composed of $43 \%$ of boys and $57 \%$ of girls (Figure 1). The age of our population is distributed in 3 groups; $50 \%$ of students who are aged between $17-19$ years, $42 \%$ aged between $20-22$ and $23-27$ (8\%), (Figure 2).

Figure 3 showed that 33\% of students have passed their exam and $67 \%$ have failed on that.

\subsubsection{Distribution and Variation of Digit Span Score's}

The graphics show the results of digit span memory distribution in our popula- 


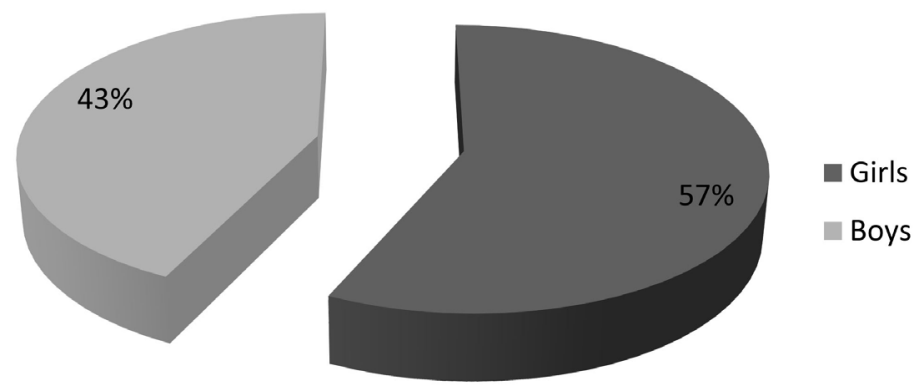

Figure 1. Distribution of students according to gender.

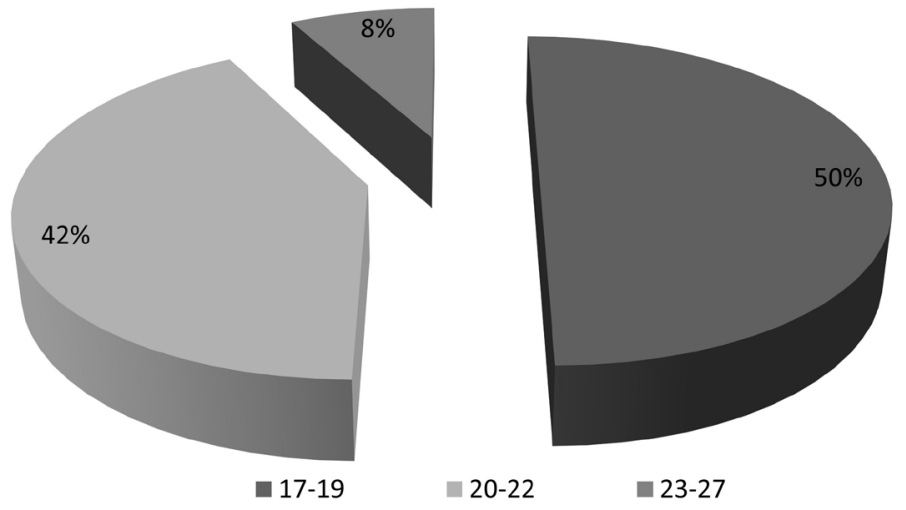

Figure 2. Distribution of students according to age.

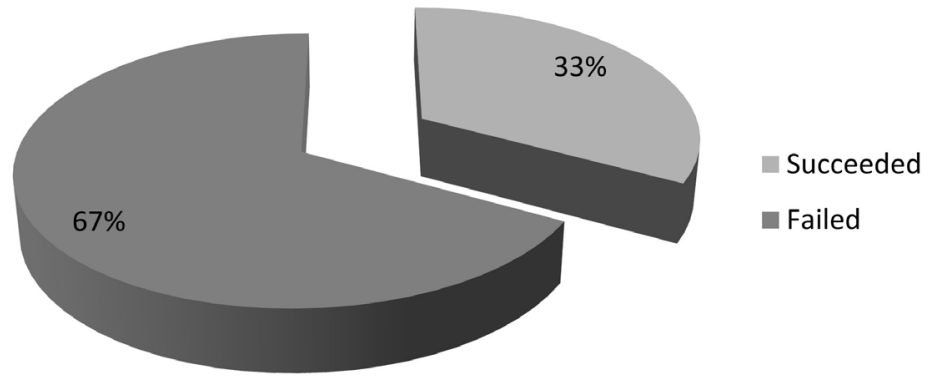

Figure 3. Distribution of students who have passed the exams of the first-year of the university.

tion; $53 \%$ of normal and $47 \%$ of excellent working memory were registered in digit span forward test, and $63 \%$ of normal, $28 \%$ excellent and $9 \%$ of pathological memory were registered in digit span backward test (See Table 1, Figure 4 and Figure 5).

\subsubsection{Distribution of Activated and Inactivated EMS}

The means presented in the EMS graphics show that some schemas are activated while others are not: Fear of loss control $(4.30 \pm 1.38)$; unrelenting standards (4.28 \pm 1.35$)$; mistrust ( $3.73 \pm 1.30)$; insufficient self-control (3.59 \pm 1.19$)$; Selfsacrifice $(3.51 \pm 1.20)$; enmeshment $(3.45 \pm 1.18)$ emotional deprivation $(3.30 \pm$ $1.31)$; vulnerability ( $3.23 \pm 1.43)$; abandonment ( $3.23 \pm 1.36)$; emotional inhibition $(3.09 \pm 1.30)$; incompetence $(2.88 \pm 1.20)$; dependence $(2.77 \pm 1.43)$; social isolation $(2.55 \pm 1.24)$ (Figure 6). 


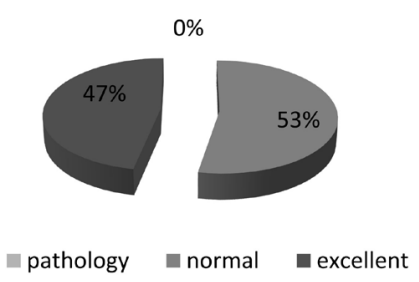

Figure 4. Working memory: Digit span forward.

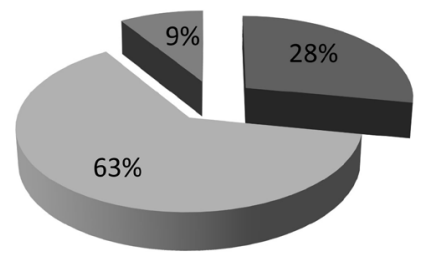

a pathology normal a exellent

Figure 5. Working memory: Digit span backward.

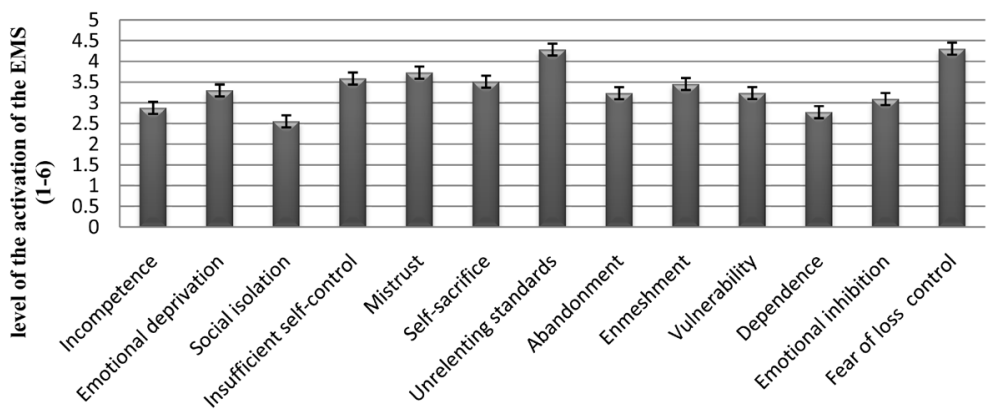

Figure 6. Mean of the 13 early maladaptive schemas with SEM.

Table 1. Mean of digit span forward and backward memory scores.

\begin{tabular}{cc}
\hline & Mean \pm SEM \\
\hline Digit span forward & $9.57 \pm 2.4$ \\
Digit span backward & $6.28 \pm 2.7$ \\
\hline
\end{tabular}

\subsection{Impact of Early Maladaptive Schemas on Working Memory}

The correlation showed that EMSs are negatively correlated to the digit span: Social isolation $(\mathrm{r}=-0.17 ; p<0.05)$, self-sacrifice $(\mathrm{r}=-0.17 ; p<0.05)$, abandonment $(\mathrm{r}=-0.16 ; p<0.05)$, \& a negative correlation with the digit span backward: Emotional deprivation $(\mathrm{r}=-0.15 ; p<0.05)$ (See Table 2).

\subsection{Impact of EMSs in the Academic Performances}

There is also a significant correlation between the different schemas and the academic performances.

A negative correlation is found between the 13 EMS and the number of modules validated in the normal session during the first semester: Incompetence: $(\mathrm{r}=$ $-0.14 ; p<0.05)$, emotional deprivation: $(\mathrm{r}=-0.15 ; p<0.05)$, social isolation: $(\mathrm{r}$ $=-0.16 ; p<0.05)$, mistrust: $(\mathrm{r}=-0.14 ; p=0.05)$, unrelenting standards: $(\mathrm{r}=$ $-0.18 ; p=0.01)$, abandonment: $(\mathrm{r}=-0.16 ; p<0.05)$ (See Table 3$)$. 
Table 2. Correlation study between EMS \& digit span.

\begin{tabular}{|c|c|c|}
\hline & Digit span forward & Digit span backward \\
\hline \multirow[t]{2}{*}{ Incompetence } & $r=0.06$ & $\mathrm{r}=0.10$ \\
\hline & $p>0.05$ & $p>0.05$ \\
\hline \multirow[t]{2}{*}{ Emotional deprivation } & $\mathrm{r}=-0.07$ & $\mathrm{r}=0.09$ \\
\hline & $p>0.05$ & $p>0.05$ \\
\hline \multirow[t]{2}{*}{ Social isolation } & $\mathrm{r}=-0.17$ & $\mathrm{r}=0.04$ \\
\hline & $p<0.05$ & $p>0.05$ \\
\hline \multirow[t]{2}{*}{ Insufficient self-control } & $\mathrm{r}=0.03$ & $\mathrm{r}=-0.11$ \\
\hline & $p>0.05$ & $p>0.05$ \\
\hline \multirow[t]{2}{*}{ Mistrust } & -0.037 & $r=-0.15$ \\
\hline & $p>0.05$ & $p<0.05$ \\
\hline \multirow[t]{2}{*}{ Self-sacrifice } & $\mathrm{r}=-0.17$ & $\mathrm{r}=-0.05$ \\
\hline & $p<0.05$ & $p>0.05$ \\
\hline \multirow[t]{2}{*}{ Unrelenting standards } & $\mathrm{r}=-0.02$ & $\mathrm{r}=-0.11$ \\
\hline & $p>0.05$ & $p>0.05$ \\
\hline \multirow[t]{2}{*}{ Abandonment } & $r=-0.16$ & $\mathrm{r}=-0.04$ \\
\hline & $p<0.05$ & $p>0.05$ \\
\hline \multirow[t]{2}{*}{ Enmeshment } & $\mathrm{r}=-0.08$ & $\mathrm{r}=-0.09$ \\
\hline & $p>0.05$ & $p>0.05$ \\
\hline \multirow[t]{2}{*}{ Vulnerability } & $\mathrm{r}=-0.12$ & $r=0.06$ \\
\hline & $p>0.05$ & $p>0.05$ \\
\hline \multirow[t]{2}{*}{ Dependence } & $\mathrm{r}=-0.13$ & $r=0.03$ \\
\hline & $p>0.05$ & $p>0.05$ \\
\hline \multirow[t]{2}{*}{ Emotional inhibition } & $\mathrm{r}=-0.01$ & $r=0.06$ \\
\hline & $p>0.05$ & $p>0.05$ \\
\hline \multirow[t]{2}{*}{ Fear of loss control } & $\mathrm{r}=-0.01$ & $\mathrm{r}=0.04$ \\
\hline & $p>0.05$ & $p>0.05$ \\
\hline
\end{tabular}

Table 3. Correlation between EMS \& the number of Units validated by students in their first year of study in university.

\begin{tabular}{cc}
\hline & The number of Units validated \\
\hline Incompetence & $\mathbf{r}=-0.14$ \\
Emotional deprivation & $p<0.05$ \\
Social isolation & $\mathbf{r}=-0.15$ \\
& $p<0.05$ \\
Insufficient self-control & $\mathbf{r}=-0.16$ \\
& $p<0.05$ \\
& $\mathrm{r}=-0.10$ \\
& $p>0.05$ \\
\hline
\end{tabular}




\begin{tabular}{|c|c|}
\hline Continued & \\
\hline Mistrust & $\mathrm{r}=-0.14$ \\
\hline & $p=0.05$ \\
\hline Self-sacrifice & $\mathrm{r}=0.02$ \\
\hline & $p>0.05$ \\
\hline Unrelenting standards & $\mathrm{r}=-0.18$ \\
\hline & $p=0.01$ \\
\hline Abandonment & $r=-0.16$ \\
\hline & $p<0.05$ \\
\hline Enmeshment & $\mathrm{r}=-0.13$ \\
\hline & $p>0.05$ \\
\hline Vulnerability & $\mathrm{r}=0.01$ \\
\hline & $p>0.05$ \\
\hline Dependence & $\mathrm{r}=-0.02$ \\
\hline & $p>0.05$ \\
\hline Emotional inhibition & $\mathrm{r}=0.02$ \\
\hline & $p>0.05$ \\
\hline Fear of loss control & $\mathrm{r}=-0.11$ \\
\hline & $p>0.05$ \\
\hline
\end{tabular}

\section{Discussion}

\subsection{EMSs and Working Memory}

The result of digit span forward memory showed that $53 \%$ of the studied samples have a normal memory and $47 \%$ have an excellent one. Moreover, regarding digit span backward memory, $63 \%$ of this sample had normal memory, $28 \%$ had an excellent memory, and $9 \%$ had a pathological one.

Also, the mean digit span backward values registered in our sample are $6.28 \pm$ 2.7 digits, and the mean digit span forward values are $9.57 \pm 2.4$. These findings converged to those found by Miller [24] regarding normal range of digit span forward $(7 \pm 2)$, and they are more important than those found by Black, regarding pathological range of digit span backward $4.0 \pm 1.3$ [25].

In addition, the present work show also, a correlation between the 13EMSs and the Digit span memory performance; a negative correlation is registered between digit span forward and social isolation, abandonment, and negative one between digit span backward and mistrust. In our knowledge, it is the first research studying this kind of relationship.

On the long form, of early maladaptive schema we generally consider any score of 3 or more to be meaningful, and on the short form, any score of 2 or more is usually meaningful.

According to the work of LeDoux, during storage in traumatic events memory, memories are supported by different systems. The conscious part (cognitive) 
memories is supported by systems involving the hippocampus and cortical areas associated with it (neocortex), while the unconscious part (emotional) would be supported by the amygdala [26]. The amygdala system is fast and automatic emotions can therefore occur before cognition. It suffices that the current situation somewhat resembles to the original traumatic situation so as to the conditional emotional response appears (activated Schema).

A number of studies have shown that measures of WM, such as digit span, correlate modestly with measures of higher level cognitive function, such as IQ [27] [28], reading [29], and arithmetic skills [30].

The lateral prefrontal cortex (LPFC) and the parietal cortex (PC) in both hemispheres are consistently shown to be involved in WM tasks. Nevertheless, the results vary as to what extent the hemispheres are involved in the execution of the tasks.

As well in Recent research, excitement has been generated by claims that working memory capacity can be trained [31] [32] [33].

Therefore we understand how the adapted schema initially becomes maladaptive with time, since the person's response to a non-traumatic situation currently in the same manner as in the past (if they were traumatic). As the lack of oversight of hazardous stimuli is a basic rule for survival, it seems that emotional memories stored in the amygdala are indelible. As the lack of over sight for dangerous stimuli, emotional memories are stored in the amygdala is indelible, it is a fundamental rule for our survival.

\subsection{EMSs and Academic Performance}

The descriptive statistic shows that our sampler is composed of $43 \%$ of boys and $57 \%$ of girls but we didn't focused in the correlation about the effect of the gender or even the age which is distributed in 3 groups; $50 \%$ of students who are aged between 17 - 19 years, 42\% aged between 20 - 22 and $23-27$ (8\%). However, academic performance can be seen in the results of correlation between EMS and academic performance. EMS show an important influence among the student's academic performance, the correlation is negative, that means when the student does not validate all of his academic modules, this is can because behind the activation of his schemas. Another cognitive and emotional source of academic anxiety is excessive is the fear of the performance and the results that are expected from academic achievement. Some individuals think that they will probably get an unsatisfactory result and it could happen at any time, which can lead to a fear.

A recent study on the EMS and anxiety done in a college in Iran, which shows the relationship between schemas, and school anxiety which is up to the standards of the individual himself to achieve their goals [34]. With regard to this study, it seems that the maladaptive scheme of "unrelenting standards" is one of the sources of the individual's unrelenting attitudes toward him/herself. When an individual faces a condition in which he/she has to function based on one his/ her unrelenting standards, internal conflicts regarding meeting or not meeting 
these standards can lead to tension and conflict which are the main components of anxiety [34].

However we didn't find a negative correlation between academic performance and EMS's but we get a mean of vulnerability show that this schemes is active in our sample, the Iranian study show that the presence of vulnerability and failure or anticipation of failure can raise the probability of increase in feeling of impaired performance. When the individual is obsessed with these ideas while studying, vulnerability of self-esteem will increase considerably and internal tension might lead to the stimulation of impaired performance scheme and they can jointly cause a blend of attritional thoughts and increase the level of pressure and failure during the process of academic performance. This proves that the work required for remediation is a work of therapy schemes.

\section{Conclusions}

We studied the EMSs and their impact on working memory and academic performance of a sample of students from IBN TOFAIL University-Kenitra.

The key findings are listed as follows:

- The results show the impact of EMSs on working memory versus the digit span: there is a negative correlation on one hand between early maladaptive schemas and span forward and span backward on the other hand.

- The impact of early maladaptive schema on academic performance represented by a negative correlation between early maladaptive schemas and the number of modules validated in the normal session during semester 1 .

The schemas that are the most activated are: Fear of loss control, unrelenting standards, mistrust, and insufficient self-control.

Taken all results together, we conclude that the evaluation of EMSs among students of the first year is a necessary indicator for preventing failures and abundant frequently encountered in this category of university students.

These results lead us to propose the establishment of a medico-psychological Center for psychological care of these students within the University by the competent authorities. Such monitoring would disable these schemes and prevent deterioration of their mental health and their academic performance as well.

\section{References}

[1] Whisman, M.A. and Uebelacker, L.A. (2006) Impairment and Distress Associated with Relationship Discord in a National Sample of Married or Cohabiting Adults. Journal of Family Psychology, 20, 369-377. https://doi.org/10.1037/0893-3200.20.3.369

[2] Muris, P. (2006) The Pathogenesis of Childhood Anxiety Disorders: Considerations from a Developmental Psychopathology Perspective. International Journal of Behavioral Development, 30, 5-11.

[3] Riso, L.P. and McBride, C. (2007) Introduction: A Return to a Focus on Cognitive Schemas. In: Riso, L.P., Du Toit, P.L., Stein, D.J. and Young, J.E., Eds., Cognitive Schemas and Core Beliefs in Psychological Problems: A Scientist Practitioner 
Guide, American Psychological Association, Washington, DC, 3-9. https://doi.org/10.1037/11561-001

[4] Rafaeli, E., Bernstein, D.P. and Young, J. (2011) Schema Therapy. Taylor and Francis Group., Routledge, 184.

[5] Dalgleish, T. (2004) Cognitive Approaches to Posttraumatic Stress Disorder: The Evolution of Multirepresentational Theorizing. Psychological Bulletin, 130, 228260. https://doi.org/10.1037/0033-2909.130.2.228

[6] McBride, C., Farvolden, P. and Swallow, S.R. (2007) Major Depressive Disorder and Cognitive Schemas. In: Riso, L.P., du Toit, P.L., Stein, D.J. and Young, J.E., Eds., Cognitive Schemas and Core Beliefs in Psychological Problems. A Scientist-Practitioner Guide, American Psychological Association, Washington, DC, 11-39. https://doi.org/10.1037/11561-002

[7] Young, J.E. and Brown, G. (1990) Young Schema Questionnaire. Cognitive Therapy Center of New York, New York, NY.

[8] Young, J.E., Klosko, J.S. and Weishaar, M.E. (2003) Schema Therapy: A Practitioner's Guide. Guilford, New York, NY.

[9] Hoffart, A., Sexton, H., Hedley, L.M., Wang, C.E., Holthe, H. and Haugum, J.A. (2005) The Structure of Maladaptive Schemas: A Confirmatory Factor Analysis and a Psychometric Evaluation of Factor-Derived Scales. Cognitive Therapy and Research, 29, 627-644. https://doi.org/10.1007/s10608-005-9630-0

[10] Torres, C. (2002) Early Maladaptive Schemas and Cognitive Distortions in Psychopathy and Narcissism. Unpublished Doctoral Dissertation, Australian National University, Canberra.

[11] Halford, G.S., Baker, R., McCredden, J.E. and Bain, J.D. (2005) How Many Variables Can Humans Process? Psychological Science, 16, 70-76.

https://doi.org/10.1111/j.0956-7976.2005.00782.x

[12] Baddeley, A.D. (2002) Is Working Memory Still Working? European Psychologist, 7, 85-97. https://doi.org/10.1027//1016-9040.7.2.85

[13] Kyllonen, P.C. and Christal, R.E. (1990) Reasoning Ability Is (Little More Than) Working-Memory Capacity? Intelligence, 14, 389-433.

[14] Daneman, M. and Tardif, T. (1987) Working Memory and Reading Skill Re-Examined. In: Coltheart, M., Ed., Attention and Performance, Erlbaum, London, Vol. 7, 491-508.

[15] Abu-Rabia, S. (2003) The Influence of Working Memory on Reading and Creative Writing Processes in a Second Language. Educational Psychology, 23, 209-222. https://doi.org/10.1080/01443410303227

[16] De Smedt, B., Ghesquiere, P. and Verschaffel, L. (2004) Working Memory and Arithmetic Abilities in Seven and Eleven Year Old Children. Paper Presented at the European Working Memory Symposium EQOMS II, Beaune.

[17] Gathercole, S.E., Pickering, S.J., Knight, C. and Stegmann, Z. (2004) Working Memory Skills and Educational Attainment: Evidence from National Curriculum Assessments at 7 and 14 Years of Age. Applied Cognitive Psychology, 18, 1-16. https://doi.org/10.1002/acp.934

[18] Baddeley, A.D. and Hitch, G. (1974) Working Memory. In: Bower, G.A., Ed., Recent Advances in Learning and Motivation, Vol. 8, Academic Press, New York.

[19] Miyake, A. and Shah, P. (1999) Toward Unified Theories of Working Memory: Emerging General Consensus, Unresolved Theoretical Issues, and Future Research Directions. In: Miyake, A. and Shah, P., Eds., Models of Working Memory: Mechanisms of Active Maintenance and Executive Control, Cambridge University Press, 
Cambridge. https://doi.org/10.1017/CBO9781139174909.016

[20] Oberauer, K., Suß, H.-M., Schulze, R., Wilhelm, O. and Wittmann, W.W. (2000) Working-Memory Capacity Facets of a Cognitive Ability Construct. Personality and Individual Differences, 29, 1017-1045.

[21] Baddeley, A.D. (1992) Working Memory. Science, 255, 556-559. https://doi.org/10.1126/science.1736359

[22] Rusinek, S. and Hautekéete, M. (2000) Instrument d'étude des schémasprécoces pour enfants (ISPE). Journal de Thérapie Comportementale et Cognitive, 9, 55-61.

[23] Schmidt, N.B., Joiner, T.E., Young, J.E. and Telch, M.J. (1995) The Schema Questionnaire: Investigation of Psychometric Properties and the Hierarchical Structure of a Measure of Maladaptive Schemata. Cognitive Therapy and Research, 19, 295321. https://doi.org/10.1007/BF02230402

[24] Miller, G.A. (1956) The Magical Number Seven, plus or minus Two: Some Limits on Our Capacity for Processing Information. Psychological Review, 63, 81-97. https://doi.org/10.1037/h0043158

[25] Black, W.F. (1986) Digit Repetition in Brain-Damaged Adults: Clinical and Theoretical Implications. Journal of Clinical Psychology, 42, 770-782. https://doi.org/10.1002/1097-4679(198609)42:5<770::AID-JCLP2270420516>3.0.CO $\underline{; 2-\mathrm{P}}$

[26] Le Doux, J.E. (1996) The Emotional Brain. Simon and Schuster, New York.

[27] Mukunda, K.V. and Hall, V.C. (1992) Does Performance on Memory for Order Correlate with Performance on Standardized Measures of Ability? A Meta-Analysis. Intelligence, 16, 81-97.

[28] Unsworth, N. and Engle, R.W. (2007) The Nature of Individual Differences in Working Memory Capacity: Active Maintenance in Primary Memory and Controlled Search from Secondary Memory. Psychological Review, 114, 104-132. https://doi.org/10.1037/0033-295X.114.1.104

[29] Swanson, H.L., Zheng, X.H. and Jerman, O. (2009) Working Memory, Short-Term Memory and Reading Disabilities: A Selective Meta-Analysis of the Literature. Journal of Learning Disabilities, 42, 260-287. https://doi.org/10.1177/0022219409331958

[30] Swanson, H.L. and Jerman, O. (2006) Math Disabilities: A Selective Meta-Analysis of the Literature. Review of Educational Research, 76, 249-274. https://doi.org/10.3102/00346543076002249

[31] Diamond, A. and Lee, K. (2011) Interventions Shown to Aid Executive Function Development in Children 4-12 Years Old. Science, 333, 959-964. https://doi.org/10.1126/science.1204529

[32] Klingberg, T. (2010) Training and Plasticity of Working Memory. Trends in Cognitive Sciences, 14, 317-324.

[33] Morrison, A. and Chein, J. (2011) Does Working Memory Training Work? The Promise and Challenges of Enhancing Cognition by Training Working Memory. Psychonomic Bulletin and Review, 18, 46-60.

[34] Isanejad, O., Heidary, M.S., Rudbari, O. and Liaghatdar, M.J. (2012) Early Maladaptive Schemes and Academic Anxiety. World Applied Sciences Journal, 18, 107112. 
Submit or recommend next manuscript to SCIRP and we will provide best service for you:

Accepting pre-submission inquiries through Email, Facebook, LinkedIn, Twitter, etc. A wide selection of journals (inclusive of 9 subjects, more than 200 journals)

Providing 24-hour high-quality service

User-friendly online submission system

Fair and swift peer-review system

Efficient typesetting and proofreading procedure

Display of the result of downloads and visits, as well as the number of cited articles Maximum dissemination of your research work

Submit your manuscript at: http://papersubmission.scirp.org/

Or contact ojmp@scirp.org 